АВДОИ Джони Титалович - соискатель Института социально-политических исследований Федерального научно-исследовательского социологического центра Российской академии наук (119333, Россия, г. Москва, ул. Фотиевой, 6, корп. 1; adt81@таil.ru)

\title{
ГЕОПОЛИТИЧЕСКИЕ ВЫЗОВЫ И РИСКИ НАЦИОНАЛЬНОЙ БЕЗОПАСНОСТИ РОССИЙСКОЙ ФЕДЕРАЦИИ НА ДАЛЬНЕМ ВОСТОКЕ
}

Аннотация. В статье представлены основные геополитические вызовы и угрозы национальной безопасности России на Дальнем Востоке. Автор производит оценку ключевых внешних и внутренних проблем макрорегиона и предлагает некоторые направления преодоления вызовов и рисков национальной безопасности на Дальнем Востоке

Ключевые слова: национальная безопасность, макрорегион, военная безопасность, экономическая безопасность

$\Pi$ онятие национальной безопасности включает в себя разные виды безопасности - государственную, общественную, информационную, экологическую, экономическую, транспортную, энергетическую и другие виды, цель которых - защита государства, общества и личности от внутренних и внешних угроз ${ }^{1}$. Содержательно национальная безопасность Российской Федерации включает в себя обеспечение реализации конституционных прав и свобод человека и гражданина, достойного уровня и качества жизни населения страны, ее суверенитета и независимости, государственной и территориальной целостности, устойчивого социально-экономического развития.

Если геополитические вызовы связаны с угрозой потери суверенитета страны и иными формами причинения ущерба ее национальным интересам, то вызовы национальной безопасности можно определить как факторы, создающие потенциальные и реальные угрозы (возможное нанесение ущерба) интересам граждан, общества и государства, но при этом одновременно являющиеся стимулами для совершенствования и развития мер по поддержанию данной безопасности.

Вопросы обеспечения национальной безопасности РФ на дальневосточном направлении постоянно находятся в центре внимания федеральных властей. Складывающуюся в настоящее время ситуацию по обеспечению национальной безопасности в Дальневосточном макрорегионе президент России В.В. Путин охарактеризовал как непростую, подчеркнув вместе с тем, что возникающие здесь угрозы хорошо известны ${ }^{2}$.

Какие это угрозы? Среди них можно назвать:

- риски потери суверенитета РФ на Дальнем Востоке вследствие оттока коренного населения и усиленных миграционных притоков, в т.ч. нелегальной миграции жителей сопредельных государств, усугубляющиеся малонаселенностью и отдаленностью макрорегиона от центральных областей России;

- риски нарастания противоречий в Азиатско-Тихоокеанском регионе

1 Указ Президента РФ от 31.12.2015 № 683 «О Стратегии национальной безопасности Российской Федерации». - Собрание законодательства РФ. 04.01.2016. № 1 (часть II). Ст. 212.

2 Совещание с постоянными членами Совета Безопасности 29.01.2021 [Электронный pесурс]. Доступ: http://kremlin.ru/events/president/news/64948. - (проверено 01.02.2021). 
(АТР) в отношениях между Соединенными Штатами Америки и Китайской Народной Республикой, что делает обстановку в этом макрорегионе мира взрывоопасной;

- риски усиления военного присутствия США и НАТО в АТР (одна из таких угроз связана с инициативой США по развертыванию систем стратегической противоракетной обороны в АТР и стратегических неядерных систем высокоточного оружия, что подрывает глобальную стабильность и нарушает сложившееся соотношение сил в ракетно-ядерной сфере) $)^{1}$;

- угрозу возможного нанесения ударов ограниченного масштаба со стороны войск США по северокорейским ядерным объектам, что имело бы катастрофические последствия для Приморского края и всего Дальнего Востока России;

- угрозу территориальных притязаний ряда сопредельных государств и связанная с этим возможность конфликтов и инцидентов на государственной границе России (в частности, вследствие неурегулированности внешних границ континентального шельфа прибрежных арктических стран в Северном Ледовитом океане» ${ }^{2}$, территориальных претензий Японии с учетом наращивания ее военной мощи);

- угрозу возрастания уровня глобальной конкуренции вокруг природного распределения стратегических ресурсов с учетом притязаний иностранных государств и транснациональных корпораций на стратегические ресурсы Арктики и Дальнего Востока ${ }^{3}$;

- риски усиления экономического и политического воздействия иностранных государств на население отдельных районов ДФО, характеризующихся низким уровнем социально-экономического развития;

- угрозу демографической и экономической экспансии Китая [Подберезкин, Боришполец, Подберезкина 2014: 67-85];

- угрозу экономической и продовольственной безопасности макрорегиона вследствие высокой себестоимости производимой продукции в ДФО и роста сравнительно дешевых товарных поставок из соседних государств;

- угрозу экологической безопасности макрорегиона вследствие незаконной предпринимательской деятельности мигрантов, в т.Ч. из соседних стран дальнего и ближнего зарубежья, на его территории;

- угрозу притязаний ряда государств на владение Северным морским путем;

1 Указ Президента РФ от 05.03.2020 № 164 «Об Основах государственной политики Российской Федерации в Арктике на период до 2035 года». - СЗ РФ. 09.03.2020. № 10. Ст. 1317; Указ Президента РФ от 25.04.2018 № 174 «Об утверждении Основ государственной пограничной политики Российской Федерации». - СЗ РФ. 30.04.2018. № 18. Ст. 2614; Указ Президента РФ от «Об Основах государственной политики Российской Федерации в Арктике на период до 2035 года» от 05.03.2020 № 164. Доступ: http://www.consultant.ru/ document/cons_doc_LAW_347129/(проверено 12.07.2021).

2 Вызовы и угрозы национальной безопасности в Российской Арктике: научно-аналитический доклад (под науч. ред. В.С. Селина, Т.П. Скуфьиной, Е.П. Башмаковой. Апатиты: КНЦ РАН. 2017

3 Указ Президента РФ от 05.03.2020 № 164 «Об Основах государственной политики Российской Федерации в Арктике на период до 2035 года». - СЗ РФ. 09.03.2020. № 10. Ст. 1317; Указ Президента РФ от 25.04.2018 № 174 «Об утверждении Основ государственной пограничной политики Российской Федерации». - СЗ РФ. 30.04.2018. № 18. Ст. 2614; Указ Президента РФ от «Об Основах государственной политики Российской Федерации в Арктике на период до 2035 года» от 05.03.2020 № 164. Доступ: http://www.consultant.ru/ document/cons_doc_LAW_347129/(проверено 12.07.2021).

4 Указ Президента РФ от 05.03.2020 № 164 «Об Основах государственной политики Российской Федерации в Арктике на период до 2035 года». - СЗ РФ. 09.03.2020. № 10. Ст. 1317. 
- риски, связанные с трансграничной организованной преступностью, терроризмом, наркотрафиком на территорию ДФО;

- угрозу деструктивного, противоправного использования «мягкой силы» для реализации интересов некоторых иностранных государств в целях оказания политического давления на Россию, вмешательства в ее внутренние дела, дестабилизации обстановки, манипулирования общественным сознанием россиян.

Однако самую серьезную озабоченность у жителей ДФО все-таки вызывают не внешние угрозы, а внутренние проблемы макрорегиона. Например, по результатам опроса, проведенного ВЦИОМом летом 2019 г., только 35\% жителей ДФО были удовлетворены доступностью медицинских услуг, лишь $40 \%$ положительно оценили состояние инфраструктуры и оснащенности медицинских объектов ${ }^{1}$. Тем не менее есть и позитивные мнения. Так, например, согласно результатам опроса, проведенного в 2020 г. Агентством по развитию человеческого капитала на Дальнем Востоке и в Арктике совместно с ВЦИОМом, 39\% респондентов положительным фактором для переезда в ДФО назвали возможность высокого заработка, 32\% - близость к АТР; $32 \%$ - благоприятную экологическую обстановку, 20\% - возможность карьерного роста $^{2}$.

В контексте уточнения существующих вызовов, рисков, угроз национальной безопасности на Дальнем Востоке и направлений для их преодоления важное значение имеет Концепция развития приграничных территорий... ${ }^{3}$, в которой четко обозначены приграничные территории, входящие в состав ДФО, а это $27 \%$ численности населения ДФО. Для этих территорий характерны те же тенденции, что и для внутренних территорий ДФО: в первую очередь это сокращение численности населения вследствие естественной убыли населения и миграции в иные регионы России (исключение здесь составляют только крупные центры, например Хабаровск, Благовещенск и пр.). Причем показатели по приграничным территориям хуже не только среднероссийских, но и показателей по ДФО в целом.

Вместе с тем следует отметить экономический, социальный, культурный и пр. потенциал приграничных территорий, входящих в состав ДФО. Например, общий плановый инвестиционный портфель этих территорий до 2025 г. включает свыше 1,6 трлн руб., что составляет 40-70\% общего объема инвестиций в основной капитал макрорегиона ДФО; имеются сельскохозяйственные угодья, позволяющие производить $1 / 3$ всей производимой продукции сельского хозяйства в макрорегионе, а также значительные запасы полезных ископаемых; данные территории имеют выгодное геостратегическое положение.

Можно выделить следующие перспективные направления преодоления вызовов и рисков национальной безопасности на Дальнем Востоке.

1. Социально-экономическое развитие всего макрорегиона Дальнего Востока, прежде всего, его приграничных территорий.

Ключевым событием для развития ДФО является запуск территорий опережающего социально-экономического развития (ТОСЭР). Так, в настоя-

1 ВЦИОМ: только 35 \% жителей Дальнего Вовстока удовлетворены доступностью медицинских услуг. Доступ: https://tass.ru/obschestvo/6604207. - (проверено 30.07.2021).

2 Россияне рассказали, зачем переезжать на Дальний Восток. Доступ: https://asn24.ru/ news/society/84850/- (проверено 31.07.2021).

3 Распоряжение Правительства РФ от 28.10.2015 №2193-р (ред. от 20.04.2019) «Об утверждении Концепции развития приграничных территорий субъектов Российской Федерации, входящих в состав Дальневосточного федерального округа». Собрание законодательства РФ. 09.11.2015. № 45. - Ст. 6287. 
щее время в ДФО созданы 22 ТОСЭР, из которых 15 находятся на территории приграничных регионов: в Республике Бурятия - 2; Забайкальском крае - 2; Приморском крае - 4; Хабаровском крае - 3; Амурской области - 3; Еврейской автономной области -1 .

В силу неравномерного развития приграничных территорий ДФО для их социально-экономического развития требуется разработка специальных программ. В частности, есть территории с относительно высоким уровнем экономического развития и концентрацией населения (например, крупные города в Хабаровском, Приморском краях, Амурской обл. и пр.); территории со средними социально-экономическими показателями, но одновременно с высоким миграционным оттоком; территории, где необходимы точечные меры для решения злободневных проблем местного населения; депрессивные регионы (например, Вяземский район в Хабаровском крае, Дальнереченский, Хорольский, Ханкайский районы в Приморском крае и пр.). Поэтому и решение проблем в этих регионах должно быть конкретным, с учетом местных особенностей, что отражается, например, в региональных программах развития приграничных муниципальных образований.

В этих программах предложен комплекс мер по улучшению демографической ситуации за счет поддержки молодых семей и специалистов, строительства и восстановления социальной инфраструктуры, повышения качества оказываемых социальных услуг и принятия мер по защите приграничных территорий от чрезвычайных ситуаций, поддержки сельского хозяйства, туристско-рекреационной деятельности, развития малого и среднего предпринимательства.

Среди важнейших направлений обеспечения национальной безопасности на российском Дальнем Востоке можно также назвать создание условий, способствующих преодолению межрегиональных различий в социально-экономическом развитии субъектов, входящих в ДФО, для чего на федеральном и региональном уровнях необходимо проводить политику, нацеленную на сбалансированность развития территорий макрорегиона.

Однако практика реализации задач социально-экономического развития регионов ДФО показывает, что принятые программы выполняются не в полном объеме. Например, проведенный в 2020 г. специалистами Института государственной службы и управления РАНХиГС анализ стратегий регионов, входящих в ДФО, показал, что только 50,2\% задач, соответствующих национальным целям и приоритетам, включены в региональные стратегии и государственные программы, 24,3\% включены частично, а 25,5\% не включены вовсе [Ильичева, Лапин 2021].

Также для примера можно привести некоторые результаты реализации Концепции развития приграничных территорий в части развития депрессивных регионов в Приморском крае, таких как Дальнереченский район, где с 2015 по 2020 г. население уменьшилось на 1100 чел.; Хорольский район - на 1922 чел.; Ханкайский район - на 1657 чел. Безусловно, какие-то меры принимаются: это и обеспечение доступным жильем; и поддержка специалистов, прибывших в приграничные населенные пункты на постоянное место жительства; и поддержка материнства и детства; и предоставление земельных участков; и внедрение информационно-поисковых систем поиска вакансий; и развитие социальной и транспортной инфраструктуры, и пр. Но, тем не менее, плотность населения Приморского края по-прежнему остается крайне невысокой - 11,5 чел. на 1 кв. км (а в 18 районах и округах менее 10 чел.).

2. Использование возможностей интеграционных процессов, осуществляе- 
мых Россией в странах АТР, при реализации программ экономического подъема Сибири и Дальнего Востока 1 .

Такое взаимодействие, с одной стороны, создает предпосылки стабильности политической ситуации в ДФО, с другой - способствует социальному и экономическому развитию субъектов, входящих в состав ДФО. Внешняя политика России на Дальнем Востоке с ее ориентацией на страны АТР реализуется через такие меры, как создание особых институциональных режимов (ТОСЭР), «свободного порта Владивосток» (СПВ), «специального административного района» (CAP), что предполагает существенные налоговые и таможенные льготы, иные преференции иностранным и российским инвесторам, реализующим совместные проекты. Например, на начало 2019 г. китайские инвестиции составили более $50 \%$ всех вложений зарубежных стран (всего в ТОСЭР и СПВ заявлено 40 инвестиционных проектов с участием КНР, общая их стоимость - 4,2 млрд долл. США 2 ).

Пандемия коронавирусной инфекции COVID-19 внесла свои коррективы в политическую реальность ДФО. Так, за 2020 г. снизился объем внешней торговли ДФО с зарубежными государствами (например, за 11 месяцев 2020 г. объем внешней торговли с Японией снизился на 22,6\% по сравнению с аналогичными показателями 2019 г., хотя японские инвесторы принимают участие в 11 проектах с общим объемом 181 млн долл. США в ТОСЭР и СПВ ${ }^{3}$ ).

3. Защита приграничных территорий Дальнего Востока от возникновения чрезвычайных ситуаций как природного, так и техногенного характера.

Это направление предполагает совместное проведение мероприятий, в частности с Монголией, Китаем, по защите от наводнений, экологическому мониторингу трансграничных водных объектов, защите от природных пожаров и пр.

4. Защита национальных интересов Российской Федерации в Арктике.

Ряд территорий Арктики расположены в пределах ДФО - все районы Чукотского автономного округа, 13 улусов Республики Саха (Якутия). В марте 2020 г. были приняты Основы государственной политики Российской Федерации в Арктике до 2035 года 4 , где определены основные национальные интересы России в этом макрорегионе, в числе которых - обеспечение высокого уровня и качества жизни его жителей и пр. Угрозы национальной безопасности в Арктическом регионе аналогичны тем, которые свойственны приграничным территориям Дальнего Востока: это малая заселенность и сокращение численности населения (например, численность населения арктических районов Республики Саха (Якутия) за последние 20 лет сократилась со 148 тыс. чел. до 68 тыс. [Оглезнева 2019]), низкий уровень развития социальной и транспортной инфраструктур, недостаточная господдержка хозяйствующих субъектов - и все это на фоне вызовов со стороны иностранных государств, стремящихся пересмотреть сложившийся здесь международно-правовой

1 Распоряжение Правительства РФ от 28.10.2015 № 2193-р (ред. от 20.04.2019) «Об утверждении Концепции развития приграничных территорий субъектов Российской Федерации, входящих в состав Дальневосточного федерального округа». - CЗ $Р \Phi$. 09.11.2015. № 45. Ст. 6287.

2 Там же.

3 Объем внешней торговли ДФО и Японии снизился на $22 \%$ из-за пандемии. - ИАА «Восток России». Доступ: https://www.eastrussia.ru/news/obem-vneshney-torgovli-dfo-iyaponii-snizilsya-na-22-iz-za-pandemii/ (проверено 12.07.2021).

4 Указ Президента РФ от 05.03.2020 № 164 «Об Основах государственной политики Российской Федерации в Арктике на период до 2035 года. - СЗ РФ. 09.03.2020. № 10. Ст. 1317. 
режим и, соответственно, создать такой его вариант, который был бы выгоден заинтересованному иностранному государству.

К этим вызовам следует добавить незавершенность разграничений морских пространств в зоне Арктики, наращивание здесь иностранного, в т.ч. военного, присутствия (речь идет в первую очередь о военном присутствии НАТО на приграничных с Россией территориях Северной Норвегии и в Баренцевом море, проведении Альянсом масштабной учебно-боевой и разведывательной деятельности вблизи государственной границы РФ в Арктике). Серьезные экономические интересы в Арктическом макрорегионе есть и у Китая, который применяет здесь так называемую арктическую дипломатию [Гусевская 2018]. В качестве вызовов можно назвать также воспрепятствование, целенаправленное ограничение иностранными лицами правомерной, исторически обусловленной хозяйственной деятельности резидентов РФ в районах, прочно связанных с Северным морским путем как транзитным транспортным коридором между Азией и Европой, пользуясь которым «можно будет уменьшить время, маршрут и стоимость доставки грузов на 30\%» [Гусевская 2018].

Важно отметить, что в качестве основных показателей эффективности выполнения программ, направленных на обеспечение национальной безопасности в зоне Арктики, названы в первую очередь демографические и социальные показатели, такие как ожидаемая продолжительность жизни при рождении; коэффициент миграционного прироста населения; уровень безработицы; число рабочих мест на новых предприятиях; средняя заработная плата работников организаций $)^{1}$.

Особое внимание уделяется обеспечению военной безопасности России в Арктике $^{2}$, что предполагает дислоцирование здесь группировки войск общего назначения Вооруженных сил РФ, способных «обеспечить военную безопасность в различных военно-политических условиях»; создание «активно функционирующей системы береговой охраны Федеральной службы безопасности Российской Федерации» [Гусевская 2018].

В связи с глобальным потеплением значение Арктического субрегиона будет динамично возрастать, что уже порождает новые вызовы, но одновременно с этим открывает и новые возможности. Например, реализация национальных интересов России в Арктике связана с принятием целого ряда проектов, в частности крупных экономических проектов по рациональному использованию природного потенциала субрегиона, созданию комплексной инфраструктуры Северного морского пути, модернизации ледокольного флота и др. Обеспечение национальных интересов России в Арктике предполагает и взаимовыгодное сотрудничество с государствами, имеющими территории в Арктической зоне.

В связи с этим настораживающе звучат высказывания из-за рубежа, что Арктика должна де-юре и де-факто принадлежать всем. Из этого следует, что каждая страна должна иметь здесь свою долю ресурсов, а Северный морской путь должен получить статус нейтральных вод [Гусевская 2018]. При этом в ряде стран, например в Китае, отсутствуют экологические нормы в

1 Постановление Правительства РФ от 21.04.2014 № 366 (ред. от 31.03.2020) «Об утверждении государственной программы Российской Федерации "Социальноэкономическое развитие Арктической зоны Российской Федерации”». - СЗ РФ. 05.05.2014. № 18 (часть IV). Ст. 2207.

2 Указ Президента РФ от 05.03.2020 № 164 «Об Основах государственной политики Российской Федерации в Арктике на период до 2035 года». - СЗ РФ. 09.03.2020. № 10. Ст. 1317. 
области добычи ресурсов, что может привести к экологической катастрофе в Арктическом субрегионе. Поэтому китайский проект «Полярный шелковый путь», включающий планы официального Пекина создать свой собственный ледокольный флот, вызывает неоднозначные оценки [Колзина, Миндубаева 2020].

При решении проблем регионального социально-политического развития ДФО можно использовать подходы, апробированные в других регионах России. В этом смысле представляет интерес предложенный Л.Е. Ильичевой и А.В. Лапиным подход к идентификации ключевых региональных проблем, заключающийся в структурировании ключевых региональных проблем по 3 группам в зависимости от их приоритетности:

1) национальные приоритеты, совпадающие с региональными приоритетами (директивно устанавливаемые проблемы, такие как низкий уровень доверия к власти, высокий уровень бедности и др.);

2) приоритеты национальных проектов, совпадающие с региональными приоритетами (такие, как недостаточный уровень образования, высокие показатели смертности населения и др.);

3) региональные приоритеты, связанные с индивидуальными особенностями региона (такие, как неудовлетворенность населения качеством оказания транспортных услуг, недостаточное обеспечение лекарственными препаратами и др.) [Ильичева, Лапин, Ножечкин 2019: 46].

Такой подход позволяет более четко ранжировать угрозы региональной безопасности по федеральному и региональным уровням, а также уточнить региональную общественную повестку дня для принятия оптимальных политических решений, направленных на противодействие вызовам глобальной нестабильности.

Однако главным ответом на вызовы национальной безопасности России на Дальнем Востоке должно стать формирование такой системы государственного управления, которая обеспечит «укоренение системы долгосрочного стратегического сотрудничества власти с населением и рыночными институтами, выстроенной на доверительной основе, способной тонко настраиваться под нужды общества в зависимости от внутренних и внешних обстоятельств во имя достижения рациональных и справедливых целей и приоритетов» [Ильичева, Лапин 2021].

\section{Список литературы}

Гусевская Н.Ю. 2018. Российско-китайское сотрудничество в Арктике: возможности и вызовы. - Государственная власть и местное самоуправление. № 6. С. 56-61.

Ильичева Л.Е., Лапин А.В. 2021. Стратегии социально-экономического развития регионов в ракурсе национальных целей и приоритетов: политический анализ: монография. М.: Аспект Пресс. 272 с.

Ильичева Л.Е., Лапин А.В., Ножечкин И.В. 2019. Ключевые проблемы региона: методы определения общественной повестки дня. - Власть. Т. 27. № 6. С. 41-57.

Колзина А.Л., Миндубаева А.А. 2020. «Полярный шелковый путь» как сфера стратегического партнерства Российской Федерации и КНР. - Вестник Удмуртского университета. Социология. Политология. Международные отношения. Т. 4. Вып. 2. С. 186-194.

Оглезнева Т.Н. 2019. Государственная политика в арктической зоне Российской Федерации и молодежная стратегия в Арктике: к постановке проблемы. - Государственная власть и местное самоуправление. № 10. С. 15-19. 
AVDOI Joni Titalovich, Applicant at the Institute of Socio-Political Studies, Federal Center of Theoretical and Applied Sociology of the Russian Academy of Sciences (bld. 1, 6 Fotievoj St, Moscow, Russia, 119333; adt81@mail.ru)

\section{GEOPOLITICAL CHALLENGES AND RISKS TO THE NATIONAL SECURITY OF THE RUSSIAN FEDERATION IN THE FAR EAST}

Abstract. The article identifies the main geopolitical challenges and threats to Russia's national security in the Far East. The author determines external threats and especially internal problems of the macroregion and proposes the directions of overcoming the challenges and risks to the national security in the Far East.

Keywords: national security, macroregion, military security, economic security

АЗИМОВ Фуркат Абдухамидович, аспирант кафедры международных отношений и политологии Нижегородского государственного лингвистического университета им. Н.А. Добролюбова (603155, Россия, г. Нижний Новгород, ул. Минина, 31a; furkat72@inbox.ru)

\section{СТРАТЕГИЯ НАЦИОНАЛЬНОЙ БЕЗОПАСНОСТИ РОССИЙСКОЙ ФЕДЕРАЦИИ}

Аннотация. Статья посвящена изучению внутренней и внешней политики, направленной на укрепление национальной безопасности Российской Федерации и обеспечение устойчивого развития страны на долгосрочную перспективу.

Ключевые слова: национализм, сепаратизм, многополярные международные отношения, национальная безопасность, национальные интересы, угроза национальной безопасности, стратегические национальные приоритеты, система обеспечения национальной безопасности, силы обеспечения национальной безопасности, полицентричная модель, мобилизационная готовность, гражданская оборона

$\mathrm{P}$ оссия преодолела последствия системного политического и социальноэкономического кризиса конца XX в. - остановила падение уровня и качества жизни российских граждан, устояла под напором национализма, сепаратизма и международного терроризма, предотвратила дискредитацию конституционного строя, сохранила суверенитет и территориальную целостность ${ }^{1}$.

Обеспечение национальной безопасности (далее - НБ) всегда являлось важнейшим направлением деятельности любого государства, в т.ч. в рамках гибкого и соответственного учета тенденций развития данного института, проявляющихся во внутригосударственной и внешней сферах, что было также закреплено в пункте м) ст. 71 Конституции РФ ${ }^{2}$. Употребление в данном пункте указанной статьи Конституции России термина «безопасность» указывает на понимание данного феномена в едином, комплексном,

1 Федеральный закон «О безопасности» от 28.12.2010 № 390-Ф3. Доступ: http://www. consultant.ru/document/cons_doc_LAW_108546/(проверено 19.07.2021).

2 Конституция РФ. Доступ: http://www.kremlin.ru/acts/constitution (проверено 19.07.2021). 